\title{
Chronic airflow obstruction in Tanzania - a cross-sectional study
}

Thomas Zoller ${ }^{1,2,3,4,5}$, Elirehema H. Mfinanga ${ }^{2}$, Tresphory B. Zumba², Peter J. Asilia ${ }^{2}$, Edwin M. Mutabazi ${ }^{2}$, David Wimmersberger ${ }^{1,5}$, Florian Kurth ${ }^{3,4}$, Francis Mhimbira ${ }^{2}$, Frederick Haraka ${ }^{1,2,5}$ and Klaus Reither ${ }^{1,5,6^{*}}$ (D)

\begin{abstract}
Background: Chronic obstructive pulmonary disease is a global problem and available data from sub-Saharan Africa is very limited.
\end{abstract}

Methods: A cross-sectional facility-based pilot study among patients and visitors to an urban and a rural primary healthcare facility was conducted in coastal Tanzania. The primary outcome was the prevalence of chronic airflow obstruction.

Results: The final analysis included 598 participants with valid post-bronchodilator spirometry. Applying ATS/ERS spirometric criteria, chronic airflow obstruction was found in $n=24$ (4\%, $\left.\mathrm{Cl}_{95} 2.7-5.9\right)$ participants and in $n=30$ (5\%, $\left.\mathrm{Cl}_{95} 3.5-7.1\right)$ applying GOLD spirometric criteria. To analyse risk factors for chronic airflow obstruction including those not meeting ATS/ERS or GOLD criteria, $\mathrm{FEF}_{25-75}$ and FEV1\% predicted was analysed in participants without evidence of pulmonary restriction among those exposed or not exposed to risk factors $(n=552)$. FEV1\% predicted, but in particular $\mathrm{FEF}_{25-75}$ decreased with increasing symptom severity of shortness of breath as well as limitations in daily activities of participants. Cooking in general and cooking with biomass fuels vs. gas or electricity was associated with significantly lower $\mathrm{FEF}_{25-75}$, but not with lower FEV1\% predicted. Participants having refrained from taking a job because of shortness of breath exhibited lower $\mathrm{FEF}_{25-75}(p<0.01)$. A history of prior active TB was the most relevant risk factor associated with a decrease in $\mathrm{FEF}_{25-75}$ as well as FEV1\% predicted.

Conclusion: This study demonstrated a relevant prevalence of chronic airflow obstruction in primary healthcare attendants and healthy visitors of a Tanzanian hospital. Using the baseline data provided, larger and populationbased studies are needed to validate these findings. TB may have more impact on development of chronic airway obstruction than smoking in Africa. Due to the influence of age on the GOLD definition of chronic airflow obstruction, studies should report results using both ATS/ERS and GOLD definitions and include age-stratified analysis. Analysis of FEV1 and in particular $\mathrm{FEF}_{25-75}$ may yield additional information on risk factors and earlier stages of chronic airflow obstruction.

Keywords: COPD, Airflow obstruction, Tuberculosis, Tanzania

\section{Background}

Chronic airflow obstruction (CAO), caused by a chronic inflammation of airways in response to exposure to dusts and fumes is a characteristic feature of chronic obstructive pulmonary disease (COPD). CAO leads to a decline in lung function and to subsequent loss of exercise capacity. Cigarette smoking is the major causative

\footnotetext{
* Correspondence: klaus.reither@swisstph.ch

${ }^{1}$ Swiss Tropical and Public Health Institute, Basel, Switzerland

${ }^{5}$ University of Basel, Basel, Switzerland

Full list of author information is available at the end of the article
}

factor for $\mathrm{CAO}$ in industrialized countries [1], leading to an overall population prevalence between $5 \%$ and $25 \%$ in Europe, North America, Latin America and Asia [2-5].

COPD is a disease mainly affecting higher age groups and most studies have so far addressed the population above the age of 40 years. Little is known however on prevalence and risk factors of COPD in developing countries with younger populations, and particularly in sub-Saharan Africa. Recently, the BOLD study investigated prevalences of $\mathrm{CAO}$ on a global level and provided data from Latin America and Asia as well as data from 
two study sites in Africa [2, 3, 6, 7]. Previous studies in sub-Saharan Africa have mostly focussed on risk groups with occupational exposure such as miners [8-11].

Epidemiology and risk factors of COPD in developing countries likely differ from those in the developed world. While cigarette smoking is less common in developing countries, factors like prolonged exposure to biomass fuels from cooking starting from early childhood, cooking indoors in rooms shared for living and sleeping purposes, high TB prevalence and different age structure have relevant influence on COPD epidemiology [12]. At present, it is unclear which effects this life-long exposure to biomass fuels in Africa has for the development of chronic obstructive pulmonary disease. Moreover, there is little data on chronic obstructive pulmonary disease in young African populations.

To gather data on CAO in Tanzania, we examined patients attending primary healthcare facilities as well as persons accompanying patients using a questionnaire and performed pre- and post-bronchodilator spirometry. Tanzanian Lung Health Study (TLHS) aims to provide first estimates on CAO in Tanzania and to explore risk factors as well as medical and social aspects of CAO, providing baseline data for further studies on a larger scale. Moreover, TLHS aims to give additional information on analysis of spirometric outcomes other than the standard definitions of CAO and their diagnostic value to detect earlier stages of small airways disease in an African setting.

\section{Methods}

A cross-sectional facility-based study was conducted among attendants, accompanying persons and visitors to the rural Bagamoyo District Hospital (Bagamoyo, Pwani, Tanzania), and the urban Mwananyamala Regional Hospital (Dar es Salaam, Tanzania) between October 2015 and September 2016. Both study centres are located in coastal Tanzania without mining industry or exposure to other region-specific lung hazards. The primary outcome was spirometric evidence of CAO. Secondary outcomes were risk factors and parameters indicating social impact. Participants were eligible for inclusion if they were at least 18 years of age and either attendants of a primary healthcare clinic for any reason other than an acute respiratory problem, persons accompanying patients or visitors to the hospital visiting inpatients. Participants visiting the hospital for other reasons, having medical contraindications against bronchodilator drugs or having any other physical or mental condition limiting the ability to obtain a valid spirometry result were excluded (hospitalisation within $<3$ months, newly diagnosed heart disease within $<3$ months, uncontrolled hypertension, resting heart rate $>100 / \mathrm{min}$., uncontrolled diabetes, pregnancy, acute infections or fever, acute pain, smoking during the last $2 \mathrm{~h}$, thoracic or abdominal surgery within $<3$ months or any other severe physical or mental disease limiting the ability to comply with instructions for spirometry). To allow analysis of outcomes in patients across all relevant age groups, age-stratified sampling was used. Within age-strata, participants were invited randomly using a predefined selection procedure.

A sample size of 600 participants was intended to provide an acceptable prevalence estimate with $2.5 \%$ precision for this pilot study assuming a prevalence of $10 \%$ of chronic airflow obstruction.

After obtaining informed consent either in writing or by an impartial witness, participants were interviewed by a trained physician or a study nurse to obtain data on lung health and TB history and trained in performing spirometry supported by a video.

After spirometry was performed, patients inhaled 4 times $100 \mu \mathrm{g}$ of salbutamol under supervision of a nurse using a spacer. Spirometry was repeated after $15 \mathrm{~min}$. Quality criteria for spirometry were applied according to the 2005 ATS/ERS guidelines [13]. Spirometer readings were checked for acceptability and repeatability criteria by the physician performing the test and checked again by a senior pulmonologist. Only spirometer readings meeting all acceptability as well as repeatability criteria (minimum grade A and B) were finally accepted. Spirometry was performed using the NDD EasyONE World Spirometer (Zürich, Switzerland). Spirometric prediction equations of the Global Lung Function Initiative for African Americans were used [14].

Spirometric data was analysed for prevalence of $\mathrm{CAO}$ applying the FEV1/FVC $<5$ th percentile predicted (LLN) method (ATS/ERS spirometric criteria) as well as the GOLD definition with a fixed FEV1/FVC ratio $<0.7$. A positive bronchodilator response was defined as an increase of FEV1 and/or FVC $>12 \%$ and at least $200 \mathrm{ml}$ compared to baseline. To further assess airflow obstruction including earlier stages, the post-bronchodilator forced expiratory flow at $25-75 \%$ of forced vital capacity $\left(\mathrm{FEF}_{25-75}\right)$ [15] and the FEV1\% predicted were used. As pulmonary restriction influences $\mathrm{FEF}_{25-75}$ and $\mathrm{FEV} 1 \%$ predicted, participants with evidence of restriction (FVC $<5$ th percentile of FVC predicted and FEV1/FVC $>0.85$, as defined by ATS/ERS criteria [16]) were excluded from this analysis.

Data was analysed using JMP ver. 14. Median FEF $_{25-75}$ and FEV1\% predicted values were compared among participants exposed vs. unexposed to risk factors for CAO. Parameters were compared between risk groups using the Mann-Whitney-U-test to compare two and the Kruskal-Wallis-Test to compare multiple groups. $\mathrm{X}_{2}$ test was used to compare categorical outcomes between groups. Differences were considered significant when $p$ was $<0.05$. 


\section{Results}

\section{Study population}

A total of 1224 participants either attending or visiting the two health facilities of the study gave informed consent. 195 participants were excluded due to violating exclusion criteria and 32 participants due to incomplete datasets. 399 patients did not produce a post-bronchodilator spirometry meeting ATS/ERS quality criteria despite intensive video-assisted training and were excluded. The study population included 598 participants with valid post-bronchodilator spirometry.

We analysed if the population of participants not able to produce a spirometry according to ATS/ERS quality criteria was different from the study population in the final analysis. Slightly more women were excluded based on this criterion ( $54.6 \%$ vs. $45.3 \%, p=0.05$ ), but there was no significant difference in terms of age (median 46 vs. 45 years, $p=0.23)$, history of active TB infection $(p=0.93)$, visitors vs. patients $(p=0.4)$, education $(p=0.46)$, reason for seeking medical attention among patients $(p=0.71)$ and smoking status $(p=0.07)$.

\section{Demographic and social characteristics}

The median age of the study population was 46 years (IQR 37-57 years) across the different age groups invited for participation, and $72 \%$ of patients were at least 40 years old (for details see Table 1). There was an equal gender distribution. The majority of participants (60\%) were visitors to the hospital or persons accompanying patients to primary healthcare clinics. The level of education was generally low, with most participants having either no $(29 \%)$ or only primary school (48\%) education. Main occupations were business and trade (29\%) as well as farming and agriculture (24\%). The leading reasons for seeking medical attention for patients attending primary healthcare clinics were infections/fevers (17\%), musculosceletal problems and injuries (15\%) and cardiovascular problems (14\%). The majority of participants cooked with charcoal (60\%) and wood (25\%), and only few participants with gas $(8 \%)$.

\section{CAO prevalence and bronchodilator response}

Applying ATS/ERS criteria, CAO was found in $n=24$ (4.0\%, $\mathrm{CI}_{95}$ 2.7-5.9) participants and $n=30\left(5.0 \%, \mathrm{CI}_{95}\right.$ 3.5-7.1) met GOLD spirometric criteria for CAO. There was an obvious difference in CAO prevalence across age groups using the two definitions. Applying ATS/ERS criteria, prevalence of CAO increased only moderately with age from $3.6 \%$ to $5.6 \%$ in 4 age groups, whereas prevalence defined by GOLD spirometric criteria was only $1.8 \%$ in participants $<40$ years of age, but $11.3 \%$ in participants $>60$ years of age (for details see Table 2). Overall, $n=46\left(7.7 \%, \mathrm{CI}_{95} 5.8-10.1\right)$ showed a positive bronchodilator response. Most participants meeting
Table 1 Demographic and social characteristics of the study population

\begin{tabular}{|c|c|c|c|}
\hline & & $\mathrm{N}$ & $\begin{array}{l}\% \text { of study } \\
\text { population }\end{array}$ \\
\hline \multirow[t]{4}{*}{ Age group } & $18-39$ & 169 & 28 \\
\hline & $40-59$ & 299 & 50 \\
\hline & $60-79$ & 124 & 21 \\
\hline & $>=80$ & 6 & 1 \\
\hline \multirow[t]{2}{*}{ Gender } & Male & 310 & 52 \\
\hline & Female & 288 & 48 \\
\hline \multirow[t]{2}{*}{ Type of participant } & Patient of hospital & 242 & 40 \\
\hline & Visitor to hospital & 356 & 60 \\
\hline \multirow[t]{4}{*}{ Education } & No formal education & 173 & 29 \\
\hline & Primary school & 289 & 48 \\
\hline & Secondary school & 99 & 17 \\
\hline & University/college & 31 & 1 \\
\hline \multirow[t]{4}{*}{ Occupation $^{a}$} & Business and trade & 172 & 29 \\
\hline & $\begin{array}{l}\text { Farming and } \\
\text { agriculture }\end{array}$ & 141 & 24 \\
\hline & Craftsmen & 38 & 6 \\
\hline & Drivers & 21 & 4 \\
\hline \multirow{6}{*}{$\begin{array}{l}\text { Reasons for seeking medical } \\
\text { attention (patients) }\end{array}$} & Infections/fevers & 41 & 17 \\
\hline & $\begin{array}{l}\text { Musculosceletal } \\
\text { problems }\end{array}$ & 35 & 15 \\
\hline & $\begin{array}{l}\text { Cardiovascular } \\
\text { problems }\end{array}$ & 33 & 14 \\
\hline & $\begin{array}{l}\text { Gastrointestinal } \\
\text { problems }\end{array}$ & 29 & 12 \\
\hline & $\begin{array}{l}\text { Non-acute respiratory } \\
\text { problems }\end{array}$ & 25 & 10 \\
\hline & $\begin{array}{l}\text { Urogenital/ } \\
\text { reproductive } \\
\text { problems }\end{array}$ & 13 & 5 \\
\hline \multirow[t]{4}{*}{ Cooking fuel } & Charcoal & 360 & 60 \\
\hline & Wood in open stove & 137 & 23 \\
\hline & Wood in open fire & 12 & 2 \\
\hline & Gas & 49 & 8 \\
\hline \multirow[t]{3}{*}{ Smoking status } & Never smoker & 435 & 73 \\
\hline & $\begin{array}{l}\text { Current or recent } \\
\text { smoker }\end{array}$ & 87 & 15 \\
\hline & $\begin{array}{l}\text { Ex-smoker } \\
\text { ( } \geq 6 \text { months } \\
\text { abstinence) }\end{array}$ & 76 & 13 \\
\hline
\end{tabular}

${ }^{\mathrm{a} O n l y ~ m a j o r}$ categories shown

either ATS/ERS or GOLD spirometric criteria had either mild or moderate levels of obstruction (see Table 3).

Correlation of symptoms and limitations of daily activities with spirometry

Current definitions of CAO only allow to define presence or absence of obstruction and may not capture 
Table 2 Prevalence of chronic airflow obstruction in the study population according to spirometric criteria of ATS/ERS using FEV1/FVC $<$ 5th percentile predicted (LLN) method or the Global Initiative for Chronic Obstructive Lung Disease (GOLD) criteria

\begin{tabular}{|c|c|c|c|c|c|}
\hline Risk factor & Group & $n$ & Meet criteria & $\%$ & $\mathrm{Cl}_{95}$ \\
\hline \multirow[t]{6}{*}{ CAO (LLN) } & All & 598 & 24 & 4.0 & $2.7-5.9$ \\
\hline & \multicolumn{5}{|c|}{ Age groups } \\
\hline & $18-39$ & 169 & 6 & 3.6 & $1.6-7.5$ \\
\hline & $40-59$ & 299 & 11 & 3.7 & $2.0-6.5$ \\
\hline & $60-79$ & 124 & 7 & 5.6 & $2.8-11.2$ \\
\hline & $>=80$ & 6 & 0 & 0 & \\
\hline \multirow[t]{6}{*}{ CAO (GOLD) } & All & 598 & 30 & 5.0 & $3.5-7.1$ \\
\hline & \multicolumn{5}{|c|}{ Age groups } \\
\hline & $18-39$ & 169 & 3 & 1.8 & $0.6-5$ \\
\hline & $40-59$ & 299 & 13 & 4.3 & $2.5-7.3$ \\
\hline & $60-79$ & 124 & 14 & 11.3 & $6.8-18$ \\
\hline & $>=80$ & 6 & 0 & 0 & \\
\hline
\end{tabular}

more subtle changes in airflow obstruction; we analysed therefore $\mathrm{FEF}_{25-75}$ as well as FEV1\% predicted values in participants without evidence of restriction $(n=552)$ in an exploratory analysis and correlated spirometric values with symptoms and limitations in daily life, and with parameters causing social impact. Participants graded the level of respiratory symptoms (shortness of breath, coughing) and social impact (limitation of daily activities or at work, limitation of activities at home) on a scale between 0 (no symptoms) and 3 (severe/frequent symptoms), and for coughing up to 4 (constant symptoms). The results are shown in Fig. 1. Symptom severity increased and indicators for social impact deteriorated with decreasing $\mathrm{FEF}_{25-75}$ and FEV1\% predicted.

Table 3 Severity of CAO according to spirometric criteria of ATS/ERS using FEV1/FVC $<5$ th percentile predicted (LLN) method or the Global Initiative for Chronic Obstructive Pulmonary Disease (GOLD) criteria

\begin{tabular}{lllll}
\hline & & $n$ & $\%$ & FEV1\% of predicted \\
\hline CAO (LLN) & All & 24 & & \\
& Very severe & 2 & 8.3 & $<35 \%$ \\
& Severe & 0 & 0 & $35-49 \%$ \\
& Moderately severe & 3 & 12.5 & $50-59 \%$ \\
& Moderate & 6 & 25.0 & $60-69 \%$ \\
& Mild & 13 & 54.2 & $\geq 70 \%$ \\
CAO (GOLD) & All & 30 & & \\
& Very severe & 2 & 6.7 & $<30$ \\
& Severe & 0 & 0 & $30-49$ \\
& Moderate & 15 & 50.0 & $50-79$ \\
& Mild & 13 & 43.3 & $\geq 80$
\end{tabular}

\section{Risk factors for airflow obstruction}

To identify risk factors promoting airflow obstruction, data from the patient interview was used to classify patients into exposed and non-exposed groups and $\mathrm{FEF}_{25-75}$ as well as $\mathrm{FEV} 1 \%$ predicted values in patients without restriction were compared. The results are given in Table 4. There was no significant difference in lung function parameters between participants who smoked or were exposed to dusts and fumes at their workplace. Cooking in general and cooking with biomass fuels vs. gas or electricity was associated with significantly lower $\mathrm{FEF}_{25-75}$, but not with lower FEV1\% predicted. The biggest and significant differences in both lung function parameters were observed between participants with a history of TB vs. those who reported no history of prior TB $(p<0.01)$. Symptoms of chronic bronchitis were associated with a decrease in both lung function parameters $(p=0.02)$. Participants having refrained from taking a job because of shortness of breath exhibited lower $\mathrm{FEF}_{25-75}$ and FEV1\% predicted values, but the difference was only significant for $\mathrm{FEF}_{25-75}$.

\section{Discussion}

Chronic airflow obstruction is an important cause of morbidity and mortality, and has major impact on the lives of those affected. Data from this pilot study in coastal Tanzania indicate a relevant level of CAO among urban and rural inhabitants. CAO can be found across all age groups and those affected may suffer from limitations in their ability to work and in quality of life.

This study showed that approximately one out of twenty inhabitants of coastal Tanzania has CAO according to both definitions currently used. Whereas the ATS/ERS definition using the LLN method showed only a moderate increase of prevalence with age, the GOLD definition showed a six-fold higher prevalence of CAO in the highest vs. the youngest age group. As the GOLD definition uses a fixed FEV1/FVC ratio of 0.7 as cut-off to define CAO, older age groups are overrepresented as the FEV1/FVC ratio declines physiologically with increasing age [17]. There is a persisting controversy on which classification to use; the LLN method indicating CAO is better suited for research purposes as it controls for ageing of the lung whereas the GOLD spirometric criteria are preferred by many clinicians due to their simplicity. The results from this study however underscore the concerns regarding over-diagnosis of elderly patients using the GOLD definition as well as potential under-diagnosis in younger patients, and demonstrate this effect in an African setting. Future epidemiological studies in Africa should therefore report results using both definitions until a universally accepted method has been developed. Moreover, results should include prevalences stratified by age groups, as exposure to biomass fuel smoke starting from birth or 


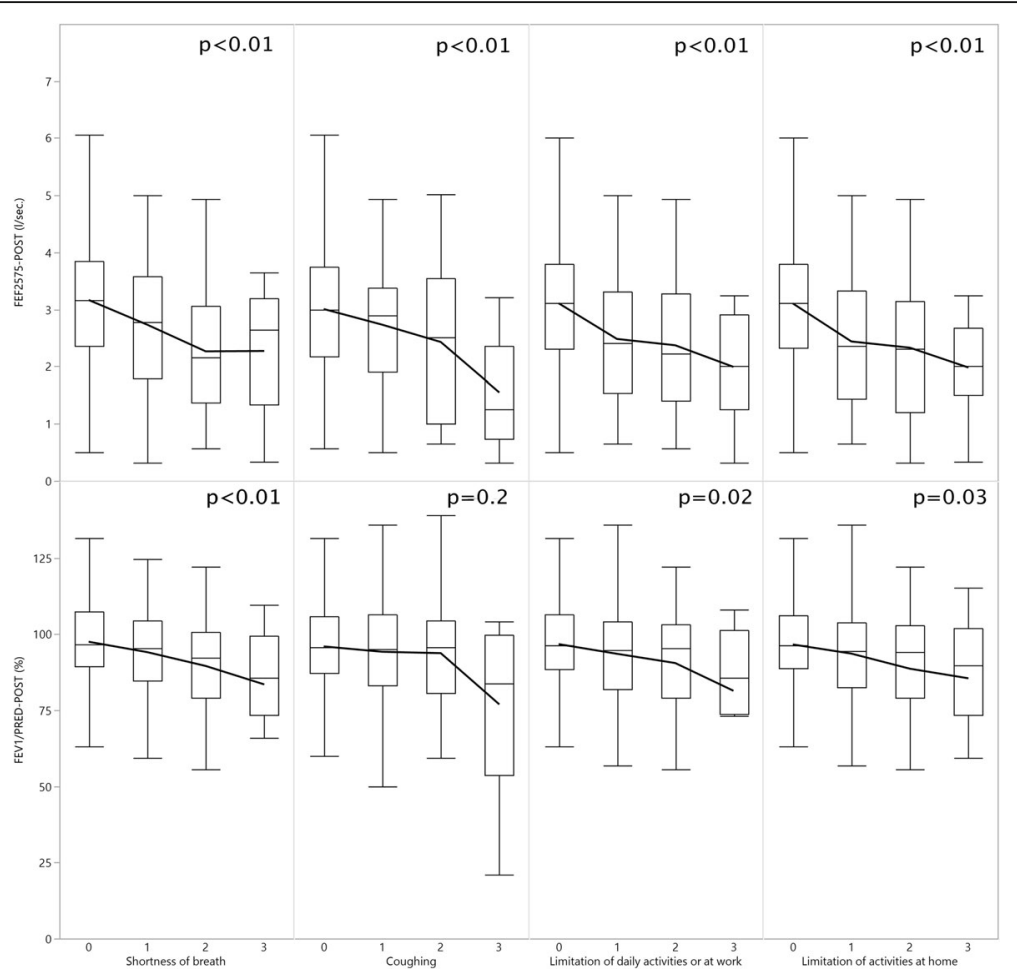

Fig. 1 Chronic airflow obstruction in relation to severity of symptoms: post-bronchodilator median FEF $25-75$ (I/s.) and FEV1 in patients without restriction by symptom severity ( 0 no symptoms, 3 severe symptoms). Boxplot shows median \& interquartile ranges and whiskers denote the furthest point within $1.5 \times$ interquartile range. Number of subjects in severity groups (from 0 to 3 ): shortness of breath $n=331,140,67,13$; coughing $n=447,75,20$, 9; limitation of daily activities or at work $n=409,84,43,15$; limitation of activities at home $n=418,81$, 38, 14, respectively. Note: the symptom "coughing" was assessed in 4 severity grades. Only one participant graded coughing with severity 4; this participant and was removed from the figure, as no boxplot could be drawn from a single value. The patient had a FEF $25-75$ of 1.99 I/s and a FEV1/PRED of 76.39\%

even in utero [12] may lead to an earlier onset and higher prevalence of $\mathrm{CAO}$ in young African populations.

Few studies have reported prevalence of $\mathrm{CAO}$ in general populations from sub-Saharan Africa not exposed to special risk factors (e.g. gold miners). The reports available so far do not give consistent results across African regions; the prevalences found in this study were lower than in a recent study from Nigeria (5.1\%-10\% (LLN)) [6], Malawi (14\% (GOLD)) [18] or from Uganda (12.4\% (LLN), 16.2\% (GOLD)) [19], but higher than in Cameroon (2.4\% (LLN), 0.5\% (GOLD)) [20]. Consistent across all studies, the majority of patients had either mild or moderate severity of obstruction. There is still no sufficient data from large population-level spirometry-based and quality-assured studies in sub-Saharan Africa to give a good CAO prevalence estimate in general or specific to African regions; the data presented in this study add relevant baseline data for planning studies on a larger scale and underscore the importance of reporting data in different age groups.

Risk factors for CAO likely differ from other regions of the world due to different living circumstances, living standards and lifestyle of populations. Smoking [1] and exposure to particulate matter [21] in the air are the predominant risk factors for $\mathrm{CAO}$ in industrialized countries. Data from China, Latin America and Turkey show a moderately increased risk of CAO after exposure to smoke from biomass fuels, with a stronger effect for firewood than for charcoal [22]. Following these principles, indoor air pollution is generally assumed to be a major risk factor in Sub-Saharan Africa [23]. Four recent studies however did not demonstrate a clear association between indoor use of biomass fuel with $\mathrm{CAO}[6,7,19,20]$. Chronic airflow obstruction may begin early in life and investigation of first signs may be missed by applying the ATS/ERS or GOLD criteria only - the predominant method of analysis used in studies from Africa. Large population based epidemiological studies have however demonstrated excellent sensitivity for early detection of airway pathology using continuous analysis of FEV1 and in particular $\mathrm{FEF}_{25-75}[21,24,25]$ as well as FEV1 as a percentage of FVC [21]. In an exploratory approach, we therefore used $\mathrm{FEF}_{25-75}$ as well as $\mathrm{FEV} 1 \%$ predicted to detect more subtle changes in airway pathology. Analysis of $\mathrm{FEF}_{25-75}$ seemed to have a higher sensitivity and better correlation with severity of symptoms and physical limitations than FEV1\% predicted. Both parameters indicated 
Table 4 Post-bronchodilator $\mathrm{FEF}_{25-75}(\mathrm{I} / \mathrm{s}$.) and $\mathrm{FEV} 1 \%$ predicted in participants without restriction, with risk factors, symptoms and limitations caused by chronic airflow obstruction in participants without evidence of restriction)

\begin{tabular}{|c|c|c|c|c|c|c|c|c|c|}
\hline & Exposure & $\mathrm{N}$ & $\begin{array}{l}\% \\
\text { of } n\end{array}$ & $\begin{array}{l}\text { Median } \mathrm{FEF}_{25-75}(\mathrm{IQR}) \text {, } \\
\text { post bronchodilator }(\mathrm{L} / \mathrm{s} \text {.) }\end{array}$ & $\begin{array}{l}\Delta \mathrm{FEF}_{25-75} \\
(\mathrm{~L} / \mathrm{s} .)\end{array}$ & p & $\begin{array}{l}\text { Median FEV1\% } \\
\text { PRED (IQR) }\end{array}$ & $\begin{array}{l}\Delta \text { FEV } 1 \% \\
\text { PRED }\end{array}$ & p \\
\hline \multirow[t]{2}{*}{ Smoking } & $\begin{array}{l}\text { Current or former } \\
\text { smoker }\end{array}$ & 155 & 28.1 & $3.1(2.15-3.76)$ & 0.2 & 0.4 & 96.44 (87.39-104.12) & 1.23 & 0.59 \\
\hline & Never smoker & 397 & 71.9 & $2.9(2.05-3.65)$ & & & 95.21 (86.14-106.34) & & \\
\hline \multirow{2}{*}{$\begin{array}{l}\text { Exposure to dusts and } \\
\text { fumes at workplace }\end{array}$} & Exposure & 442 & 80.1 & $2.97(2.03-3.7)$ & 0.19 & 0.78 & 95.15 (85.94-104.42) & 3.74 & 0.07 \\
\hline & No exposure & 110 & 19.9 & $2.78(2.2-3.63)$ & & & 98.88 (89.31-107.82) & & \\
\hline \multirow[t]{2}{*}{ Cooking } & Regular cooking & 317 & 57.4 & $2.74(1.93-3.47)$ & 0.43 & $<0.01$ & 95.19 (85.61-105.79) & 0.2 & 0.12 \\
\hline & No regular cooking & 231 & 41.8 & $3.16(2.34-3.99)$ & & & 95.39 (88.62-105.37) & & \\
\hline \multirow[t]{2}{*}{ Biomass fuels for cooking } & $\begin{array}{l}\text { Cooking with } \\
\text { wood or coal }\end{array}$ & 472 & 85.5 & $2.84(1.96-3.61)$ & 0.53 & $<0.01$ & 95.15 (85.62-104.93) & 1.33 & 0.39 \\
\hline & $\begin{array}{l}\text { Cooking with gas } \\
\text { or electricity }\end{array}$ & 47 & 8.5 & $3.36(2.5-3.99)$ & & & 96.47 (72.93-106.29) & & \\
\hline \multirow[t]{2}{*}{ History of active TB } & History of active TB & 71 & 12.9 & $2.07(1.5-3.12)$ & 0.95 & $<0.01$ & $96.2(87.48-106.34)$ & 6.34 & $<0.01$ \\
\hline & No history of active TB & 481 & 87.1 & $3.02(2.23-3.71)$ & & & 89.86 (77.11-101.86) & & \\
\hline \multirow{2}{*}{$\begin{array}{l}\text { Chronic bronchitis } \\
\text { (chronic cough and sputum) }\end{array}$} & Yes & 46 & 8.3 & $2.41(1.44-3.49)$ & 0.58 & 0.02 & 90.73 (74.02-103.34) & 4.86 & 0.02 \\
\hline & No & 506 & 91.7 & $2.99(2.1-3.67)$ & & & 95.6 (86.89-105.86) & & \\
\hline \multirow{2}{*}{$\begin{array}{l}\text { Having ever refrained } \\
\text { from taking a job because } \\
\text { of shortness of breath }\end{array}$} & Yes & 87 & 15.8 & $2.43(1.56-3.28)$ & 0.6 & $<0.01$ & 95.25 (81.58-103.25) & 0.28 & 0.14 \\
\hline & No & 465 & 84.2 & $3.02(2.17-3.71)$ & & & 95.53 (86.99-105.96) & & \\
\hline
\end{tabular}

differences among participants exposed and unexposed to risk factors for CAO typical for an African setting and indicated their potential significance for causing social impact. We therefore recommend that in larger studies on CAO in Africa, results should be reported both using the standard CAO definitions, but also using analysis of continuous spirometric values such as $\mathrm{FEF}_{25-75}$ and $\mathrm{FEV} 1 \%$ predicted.

Recent meta-analyses and studies on a global scale were able to demonstrate that active tuberculosis as an infection causing chronic pulmonary inflammation over a prolonged period of time is a major factor contributing to CAO [26-28]. In this study, a history of active TB infection was the most relevant risk factor associated with a lower $\mathrm{FEF}_{25-75}$ as well as a lower FEV1\% predicted. The observed effect of TB infection is consistent with other recently published studies from local African populations $[6,18,29]$ and underscores the significance of TB for development of chronic lung disease in Africa.

This study had limitations. In order to examine CAO in a sufficient number of subjects in each age class in this study, age-stratified sampling was used. The population sample examined consisted of a mixed population composed of hospital visitors and patients. Therefore, particularly the prevalence of CAO should not necessarily be regarded as representative for the general population. An unexpectedly high number of study participants was unable to produce a spirometry meeting ATS/ERS quality criteria despite intensive and standardized pre- spirometry training including a training video two times. In previous studies in developing country settings in Latin America and Africa [6, 19, 30], observed spirometry failure rates were lower except for one study from Malawi with a similar rate of exclusions [7]. Local cultural and religious factors in this community causing people not to expose themselves in a medical examination requiring their participation with maximum muscular force used, together with a generally low level of education probably have contributed to this high failure rate. Main findings in this study, particularly with regard to risk factors for $\mathrm{CAO}$ need to be confirmed in larger population-based studies.

\section{Conclusions}

In conclusion, this study demonstrated a relevant burden of CAO in a Tanzanian population and showed major differences in prevalence as well as age-specific prevalence between the two standard definitions of $\mathrm{CAO}$ used. Although most individuals with evidence of CAO had only mild or moderate obstruction, CAO likely has relevant social and social and economic impact for those affected. TB may have more impact on development of chronic airway obstruction than smoking in Africa. Analysis of FEV1 and $\mathrm{FEF}_{25-75}$ in epidemiologic studies on CAO may give important information on risk factors and impact in addition to using standard definitions for CAO alone. 


\section{Abbreviations}

ATS/ERS: American Thoracic Society/European Respiratory Society; BOLD: Burden of Obstructive Lung Disease Initiative; CAO: Chronic airflow obstruction; COPD: Chronic obstructive pulmonary disease; FEF: Forced exspiratory flow; FEV1: Forced expiratory volume in $1 \mathrm{~s}$; FVC: Forced vital capacity; GOLD: Global Initiative for Chronic Obstructive Lung Disease; LLN: Lower limit of normal; TB: Tuberculosis

\section{Acknowledgements}

Not applicable.

\section{Funding}

Rudolf Geigy Foundation, Basel, Switzerland.

\section{Availability of data and materials}

The datasets used and/or analysed during the current study are available from the corresponding author on reasonable request.

\section{Authors' contributions}

TZ, EHM, DW and KR conceived the study. TBZ, PJA recruited patients and performed spirometry under supervision of TZ, EHM, FM, FH. All authors contributed to and revised the final manuscript. All authors read and approved the final manuscript

\section{Ethics approval and consent to participate}

The study was approved by the ethical committee of Ifakara Health Institute, Dar es Salaam, Tanzania, the National Institute for Medical Research (NIMR) in Dar es Salaam, Tanzania (NIMR/HQ/R.8c/Nol. II/633), and the responsible ethical committee of Swiss Tropical and Public Health Institute (Ethikkommission Nordwest und Zentralschweiz), Basel, Switzerland (EKNZ UBE-15/16). All participants provided written informed consent before participation in the study.

\section{Consent for publication}

Not applicable.

\section{Competing interests}

All authors declare no competing interest.

\section{Publisher's Note}

Springer Nature remains neutral with regard to jurisdictional claims in published maps and institutional affiliations.

\section{Author details}

'Swiss Tropical and Public Health Institute, Basel, Switzerland. ${ }^{2}$ ffakara Health Institute, Dar es Salaam, Tanzania. ${ }^{3}$ Charité - Universitätsmedizin Berlin, corporate member of Freie Universität Berlin, Humboldt-Universität zu Berlin, and Berlin Institute of Health, Berlin, Germany. ${ }^{4}$ Department of Infectious Diseases and Respiratory Medicine, Charité - Universitätsmedizin Berlin, Berlin, Germany. ${ }^{5}$ University of Basel, Basel, Switzerland. ${ }^{6}$ Clinical Research Unit, Schweizerisches Tropen- und Public Health Institut, Socinstr. 57, 405 Basel, Switzerland.

Received: 21 September 2017 Accepted: 4 January 2018

Published online: 19 January 2018

\section{References}

1. Vogelmeier CF, Criner GJ, Martinez FJ, et al. Global Strategy for the Diagnosis, Management, and Prevention of Chronic Obstructive Lung Disease 2017 Report: GOLD Executive Summary. Eur Respir J. 2017;49: 1700214. [https://doi.org/10.1183/13993003.00214-2017].

2. Buist AS, McBurnie MA, Vollmer WM, Gillespie S, Burney P, Mannino DM, et al. International variation in the prevalence of COPD (the BOLD study): a population-based prevalence study. Lancet. 2007:370:741-50.

3. Menezes AMB, Perez-Padilla R, Jardim JRB, Muiño A, Lopez MV, Valdivia G, et al. Chronic obstructive pulmonary disease in five Latin American cities (the PLATINO study): a prevalence study. Lancet Lond Engl. 2005:366:1875-81.

4. Caballero A, Torres-Duque CA, Jaramillo C, Bolívar F, Sanabria F, Osorio P, et al. Prevalence of COPD in five Colombian cities situated at low, medium, and high altitude (PREPOCOL study). CHEST J. 2008;133:343-9.
5. WHO | Causes of COPD [Internet]. WHO. [cited 2017 Apr 3]. Available from: http://www.who.int/respiratory/copd/causes/en/

6. Obaseki DO, Erhabor GE, Gnatiuc L, Adewole OO, Buist SA, Burney PG. Chronic airflow obstruction in a black African population: results of BOLD study, Ile-Ife, Nigeria. COPD J Chronic Obstr Pulm Dis. 2016;13:42-9.

7. Meghji J, Nadeau G, Davis KJ, Wang D, Nyirenda MJ, Gordon SB, et al. Noncommunicable lung disease in sub-Saharan Africa. A community-based cross-sectional study of adults in urban Malawi. Am J Respir Crit Care Med. 2016:194:67-76.

8. Park HH, Girdler-Brown BV, Churchyard GJ, White NW, Ehrlich RI. Incidence of tuberculosis and HIV and progression of silicosis and lung function impairment among former Basotho gold miners. Am J Ind Med. 2009:52:901-8.

9. Ehrlich RI, Myers JE, te Water Naude JM, Thompson ML, Churchyard GJ. Lung function loss in relation to silica dust exposure in south African gold miners. Occup Environ Med. 2011;68:96-101.

10. Hamatui N, Naidoo RN, Kgabi N. Respiratory health effects of occupational exposure to charcoal dust in Namibia. Int J Occup Environ Health. 2016;22:3, 240-48. https://doi.org/10.1080/10773525.2016.1214795.

11. Isara AR, Adam VY, Aigbokhaode AQ, Alenoghena IO. Respiratory symptoms and ventilatory functions among quarry workers in Edo state, Nigeria. Pan Afr Med J. 2016;23:212.

12. Eisner MD, Anthonisen N, Coultas D, Kuenzli N, Perez-Padilla R, Postma D, et al. An official American Thoracic Society public policy statement: novel risk factors and the global burden of chronic obstructive pulmonary disease Am J Respir Crit Care Med. 2010;182:693-718.

13. Miller MR. Standardisation of spirometry. Eur Respir J. 2005;26:319-38.

14. Quanjer PH, Stanojevic S, Cole TJ, Baur X, Hall GL, Culver BH, et al. Multiethnic reference values for spirometry for the 3-95-yr age range: the global lung function 2012 equations. Eur Respir J. 2012:40:1324-43.

15. McNulty W, Usmani OS. Techniques of assessing small airways dysfunction. Eur. Clin Respir J. 2014;1:25898.

16. Pellegrino R. Interpretative strategies for lung function tests. Eur Respir J. 2005:26:948-68

17. Do not adopt the GOLD definition [Internet]. [cited 2017 Apr 5]. Available from: http://spirxperters-education.org/en/gold-controversy/background/

18. Fullerton DG, Suseno A, Semple S, Kalambo F, Malamba R, White S, et al. Wood smoke exposure, poverty and impaired lung function in Malawian adults. Int J Tuberc Lung Dis. 2011;15:391-8.

19. van Gemert F, Kirenga B, Chavannes N, Kamya M, Luzige S, Musinguzi P, et al. Prevalence of chronic obstructive pulmonary disease and associated risk factors in Uganda (FRESH AIR Uganda): a prospective cross-sectional observational study. Lancet Glob Health. 2015:3:e44-51.

20. Pefura-Yone EW, Kengne AP, Balkissou AD, Magne-Fotso CG, Ngo-Yonga M, Boulleys-Nana JR, et al. Prevalence of obstructive lung disease in an African country using definitions from different international guidelines: a community based cross-sectional survey. BMC Res Notes. 2016;9:124

21. Downs SH, Schindler C, L-JS L, Keidel D, Bayer-Oglesby L, Brutsche MH, et al. Reduced exposure to PM10 and attenuated age-related decline in lung function. N Engl J Med. 2007;357:2338-47

22. Kurmi OP, Semple S, Simkhada P, Smith WCS, Ayres JG. COPD and chronic bronchitis risk of indoor air pollution from solid fuel: a systematic review and meta-analysis. Thorax. 2010:65:221-8.

23. Perez-Padilla R, Schilmann A, Riojas-Rodriguez H. Respiratory health effects of indoor air pollution. Int. J. Tuberc. Lung dis. Off. J. Int. Union Tuberc Lung Dis. 2010;14:1079-86.

24. Avol EL, Gauderman WJ, Tan SM, London SJ, Peters JM. Respiratory effects of relocating to areas of differing air pollution levels. Am J Respir Crit Care Med. 2001;164:2067-72.

25. Gauderman WJ, Gilliland GF, Vora H, Avol E, Stram D, McConnell R, et al. Association between air pollution and lung function growth in southern California children: results from a second cohort. Am J Respir Crit Care Med. 2002;166:76-84

26. Amaral AFS, Coton S, Kato B, Tan WC, Studnicka M, Janson C, et al. Tuberculosis associates with both airflow obstruction and low lung function: BOLD results. Eur Respir J. 2015:46:1104-12.

27. Byrne AL, Marais BJ, Mitnick CD, Lecca L, Marks GB. Tuberculosis and chronic respiratory disease: a systematic review. Int J Infect Dis. 2015;32:138-46.

28. Menezes AMB, Hallal PC, Perez-Padilla R, Jardim JRB, Muino A, Lopez MV, et al. Tuberculosis and airflow obstruction: evidence from the PLATINO study in Latin America. Eur Respir J. 2007;30:1180-5. 
29. Manji M, Shayo G, Mamuya S, Mpembeni R, Jusabani A, Mugusi F. Lung functions among patients with pulmonary tuberculosis in Dar es Salaam - a cross-sectional study. BMC Pulm Med. 2016;16:58. https://doi.org/10.1186/ s12890-016-0213-5.

30. Idolor LF, De Guia TS, Francisco NA, Roa CC, Ayuyao FG, Tady CZ, et al. Burden of obstructive lung disease in a rural setting in the Philippines: BOLD in a rural Philippines community. Respirology. 2011;16:1111-8.

Submit your next manuscript to BioMed Central and we will help you at every step:

- We accept pre-submission inquiries

- Our selector tool helps you to find the most relevant journal

- We provide round the clock customer support

- Convenient online submission

- Thorough peer review

- Inclusion in PubMed and all major indexing services

- Maximum visibility for your research

Submit your manuscript at www.biomedcentral.com/submit
Biomed Central 